\title{
REGRAS DE GOVERNANÇA: PRESSUPOSTOS DE EFICIÊNCIA E \\ QUALIDADE NA GESTÃO SUSTENTÁVEL DA ADMINISTRAÇÃO \\ PÚBLICA.
}

\section{GOVERNANCE RULES: EFFICIENCY AND QUALITY ASSUMPTIONS IN SUSTAINABLE PUBLIC ADMINISTRATION MANAGEMENT.}

\author{
Maria Cláudia da Silva Antunes de Souza ${ }^{1}$ \\ Eduardo Teixeira de Souza ${ }^{2}$
}

\section{RESUMO}

Regras de governabilidade eficientes são atributos intrínsecos necessários à Administração Pública. Em vista disso, a gestão sustentável, transparente, célere, econômica dos atos da Administração Pública se mostrou mais que necessária, mostrouse imprescindível como pressuposto fundamental da correta e adequada aplicação dos recursos orçamentários do Estado, o dinheiro público. Nesse sentido, compreender as regras de governança como instrumentos de qualidade e eficiência na Administração Pública permite o desenvolvimento de uma gestão sustentável em benefício do cidadão, contribuinte do Estado. Desta forma, por meio da pesquisa bibliográfica, foram selecionadas as fontes necessárias a demonstração do núcleo da problemática e, valendose do método indutivo se desenvolveu a pesquisa, com o objetivo de estabelecer a adequada observação e compreender como as regras de governança privada foram emprestadas e aplicadas à Administração Pública, servindo-se como pressuposto de boa gestão e sustentabilidade da estrutura administrativa do Estado.

PALAVRA-CHAVE: Governança; Administração Pública; Eficiência; Sustentabilidade.

\begin{abstract}
Efficient governance rules are intrinsic attributes necessary for public administration. In view of this, the sustainable, transparent, speedy and economic management of Public

\footnotetext{
${ }^{1}$ Doutora e Mestre em Derecho Ambiental y de la Sostenibilidad pela Universidade de Alicante - Espanha. Mestre em Ciência Jurídica pela Universidade do Vale do Itajaí - Brasil. Professora Permanente no Programa de Pós-Graduação Stricto Sensu em Ciência Jurídica, nos cursos de Doutorado e Mestrado e, na Graduação no Curso de Direito da Universidade do Vale do Itajaí - UNIVALI. E-mail: mclaudia@univali.br. Orcid: https://orcid.org/0000-0002-8118-1071.

${ }^{2}$ Doutorando em Ciência Jurídica pela Universidade do Vale do Itajaí com dupla titulação em convênio com a Universidade de Alicante/ES. Mestre em Direito pela Universidade Caxias do Sul. Procurador jurídico da Ordem dos Advogados do Brasil - Seção de Santa Catarina. E-mail: aulus@edsadv.com.br
} 
Administration acts proved to be more than necessary, and proved essential as a fundamental assumption of the correct and adequate application of the State budget resources, the public money. In this sense, understanding the rules of governance as instruments of quality and efficiency in Public Administration allows the development of sustainable management for the benefit of the citizen, State taxpayer. Thus, through bibliographic research, the necessary sources were selected to demonstrate the core of the problem and, using the inductive method, the research was developed, with the objective of establishing the proper observation and understanding how the rules of private governance were loaned and applied to the Public Administration, serving as an assumption of good management and sustainability of the administrative structure of the State.

\section{KEY-WORDS}

Governance; Public administration; Efficiency; Sustainability.

\section{INTRODUÇÃO}

Desde que a emenda constitucional n. 19/98 introduziu a Eficiência no conjunto de Princípios que orientam a Administração Pública no rol fixado pelo art.37 do texto constitucional trouxe, não obstante, por via reflexa regras de governança administrativa do setor privado para a esfera pública, com a objetiva finalidade de aumentar a qualidade do serviço público prestado com a menor onerosidade possível.

Portanto, o exercício prático das atribuições dos gestores públicos, neste incluindo-se além dos agentes políticos, os agentes públicos comissionados, bem como, os servidores efetivos, revestiu-se de ampla necessidade de atender ao cidadão com maior transparência, eficácia, critérios essenciais e objetivos que utilizasse da maneira mais eficiente os recursos econômicos financeiros decorrentes das arrecadações tributárias e fiscais da Sociedade.

Nesse sentido é que se justifica o presente texto, o qual tem por finalidade demonstrar que as regras de governança administrativa privada importadas para a Administração Pública se tornaram pressupostos de eficácia e efetividade nos atos da boa gestão pública, cujo conjunto da obra permite o encadeamento de ações em benefício da Sociedade de forma sustentável e de qualidade com vistas ao emprego cauteloso e equilibrado do dinheiro do contribuinte.

Desta forma, por meio da pesquisa bibliográfica, valendo-se do método indutivo é que a pesquisa foi desenvolvida, com a objetiva finalidade de subsidiar a 
observação e compreensão mais aprofundada das regras de governança privada aplicadas a Administração Pública.

Para tanto, busca-se estabelecer como marco inicial, a compreensão do conceito de eficiência, bem como, a origem da expressão "governança corporativa" como regra fundamental e orientadora dos atos administrativos no setor privado, cuja expressão restou incorporada ao setor público como pressuposto de eficiência da gestão administrativa do Estado.

Concebido na carta Magna, o princípio da eficiência levou o Estado a se aperfeiçoar em todos os sentidos, desde sua aparelhagem tecnológica estrutural até seus recursos humanos.

Desta forma, fundado nas regras originais descritas no art. 37 do texto constitucional, princípios que orientam a Administração Pública, Direta e Indireta, fundacional e Autárquica, o sistema de gerenciamento administrativo passou por uma substancial transformação, cujas características demonstrou que se priorizava a gestão responsável, legalista e de respeito intransigente ao interesse público, estabelecendo regras de governança e boa gestão sustentável no setor a cada ano.

\section{QUALIDADE E EFICIÊNCIA NA PRESTAÇÃO DE SERVIÇO PÚBLICO}

Inserto no artigo 37 do texto constitucional brasileiro pela emenda constitucional n. 19/98, o Princípio da Eficiência ousou elevar a qualidade com que os agentes públicos prestavam o serviço do Estado em favor do cidadão.

A principal intenção com a referida Emenda era fixar regras fundamentais de importância organo-funcional no gerenciamento administrativo da máquina pública, de forma a promover verdadeira catarse no sistema gerencial brasileiro, alterando-o de seu aspecto burocrático para um sistema com características metódicas gerenciais, cuja origem ocorreu a partir do Plano Diretor de Reforma do Aparelho do Estado em 1995.

Por este motivo é que a Eficiência foi concebida no rol principiológico da regra matriz que orienta a Administração Pública, exigindo, sobretudo, a escorreita adequação dos atos administrativos a particularidade da situação que o reveste. Em outras palavras, por Princípio, tem-se a origem, portanto, trata-se de enunciado balizador que 
estabelece a qualidade dos serviços prestados pelos agentes da administração estatal, orientando ações discricionárias ou não, com a menor onerosidade e maior efetividade.

O gestor público tem por dever absoluto de agir sob a premissa dos melhores e mais bem aferíveis resultados proporcionalmente esperados pelo cidadão. E, a despeito de submeter-se ao controle do Poder Judiciário, nos termos da ampla legalidade, as ações dimensionadas por este princípio conferem economia, transparência e qualidade nos resultados disponibilizados com a prestação do serviço das Políticas Públicas.

O Princípio da Eficiência é justificado então, pela racional e justa entrega de serviços prestados pelo Estado ao Cidadão.

De forma que é possível compreender que existem atributos intrínsecos no Princípio da Eficiência que permitem eclodir, manifestar a qualidade da prestação de serviços da Administração pública. Aspectos caracterizadores da racionalidade, celeridade e economicidade que conglobam a entregam de serviços adequada pelo Estado.

Os referidos aspectos são manifestações decorrentes da aplicação de regras e procedimentos padronizados, os quais são denominados no setor privado de regras de governança.

No setor privado, Wald $^{3}$ a define como a união de diretrizes para melhorar o desempenho de uma empresa.

Portanto, é possível inferir que no setor público as regras de governança incorporam além dos atributos naturais do princípio da eficiência, também a transmissão e transparência no fluxo de informações e, consequentemente, os meios pelos quais essas informações são compartilhadas a partir da entrega da prestação de serviço ao cidadão.

Para que se posse alcançar a qualidade esperada na prestação de serviços da administração pública, é necessário que se estabeleçam regras de governança que guiarão os agentes na direção dos interesses dos indivíduos de forma estável e permanente sustentável - e, sobretudo, sob o estrito ditame da legalidade administrativa.

Sem a pretensão de esgotar o assunto, é possível constatar acerca da existência de pelo menos quatro atributos fundamentais que revestem o Princípio da

\footnotetext{
${ }^{3}$ WALD, Arnoldo; MORAES, Luiza. Alguns aspectos do controle e da gestão de companhias no projeto de reforma da lei das sociedades por ações - considerações gerais. Revista de Direito Bancário, do Mercado de Capitais e da Arbitragem. São Paulo, v.3, n. 8, p. 13-30, abr./jun. 2000. p. 53.
} 
Eficiência conformando os principais aspectos qualitativos da prestação de serviço público, são eles: a Racionalidade, Produção, Economia, Rapidez ${ }^{4}$.

Os referidos atributos contribuem com efetividade sobre a orientação concreta emprestada a finalidade da existência principiológica a bem do interesse público, porquanto, a despeito de configurar-se como normativa principiológica constitucional, o princípio que encerra os mencionados atributos nada mais é que os consequentes procedimentos dos atos de boa administração, o que seria efetiva obrigação funcional de qualquer agente público, seja ele político ou não.

Nesse sentido, racionalizar é verbo consistente no desenvolvimento de atribuição com a menor quantidade de incorreções possíveis de um processo produtivo. Assim, poder-se-ia dizer que se a produção foi eficiente, não obstante, apenas pela racionalidade de um processo não se pode atribuir eficiência absoluta, haja vista o grau de subjetivismo que se pode empregar, inclusive sob outros aspectos ${ }^{5}$.

Desta forma, a racionalização complementa-se pela economicidade, a qual decorre do melhor resultado produtivo com o menor custo possível despendido com os meios empregados. Ou seja, o maior rendimento dos meios promoverá uma consequente dilação produtiva.

É assim, sobretudo, uma razoável justificativa para o paradigma epistemológico dos processos de governança administrativa no setor privado. Trata-se objetivamente da valorização do trabalho desenvolvido pelo servidor público de forma consciente e dedicada buscando o melhor resultado e emprego dos meios de produção a bem do interesse coletivo.

Assim, se de um lado a racionalização é resultante da interação do produto e as ferramentas de manejo utilizadas para otimizar o resultado, de outro lado, a economicidade é resultado da utilização dos meios, do menor custo e, portanto, dos rendimentos obtidos a partir desse binário. Com efeito, são atributos homônimos na essência ${ }^{6}$.

\footnotetext{
${ }^{4}$ MORAES, Alexandre de. Reforma Administrativa: Emenda Constitucional $\mathbf{n}^{\circ}$ 19/98. 3. ed., São Paulo: Atlas, 1999, p. 30.

${ }^{5}$ TOURAINE, Alain. Crítica da modernidade. Rio de Janeiro: Vozes, 1994, p. 99.

${ }^{6}$ ALFONSO, Luciano Parejo. Eficacia y administración: tres estudios. Madrid: Imprenta Nacional del Boletín Oficial del Estado, 1995.
} 
Não obstante, a produtividade e a celeridade, são atributos que encerram a efetividade do trabalho prestado pelo servidor ao utilizar eventuais regras de governança - medidas de coordenação e controle - para desenvolver suas atribuições.

Ao realizar suas atribuições com rapidez a partir de um método adequado, o operador do processo valer-se-á de um encadeamento de ações para alcançar o resultado de sua produção, permitindo, assim, influenciar diretamente na relação custo-benefício da qualidade do serviço entregue ao cidadão.

Ocorre que de uma forma ou de outra, a Eficiência na prestação de serviços da Administração Pública está diretamente ligada na economicidade, na celeridade, nos resultados decorrentes da produtividade e, consequentemente, nos resultados qualitativos da Administração do Estado.

Por essas razões é preciso fixar regras de governança e boa gestão no setor público, afim de permitir que o Estado entregue ao cidadão uma prestação de serviços com qualidade e organização de excelência.

Outrossim, esclarece Alexandre de Moraes que todos esses aspectos mencionados acerca do princípio da eficiência visam garantir o bem da Sociedade evitando desperdícios com recursos orçamentários, por meio da adoção dos melhores critérios jurídicos que encerrem a maior e melhor qualidade ao atendimento do bem comum, cuja plataforma se sustenta na participação social, transparência, eficácia das políticas públicas, imparcialidade competencial ${ }^{7}$.

Portanto, não pode haver uma interpretação isolada do princípio em apreço sem que sejam considerados seus atributos e as regras de governança que o orientam, sob pena de haver um desvirtuamento de sua principal finalidade: atender com qualidade o cidadão tomador de serviços da Administração Pública, possibilitando a economia dos recursos orçamentários que abastecem o Estado.

\section{SUSTENTABILIDADE E GOVERNANÇA CORPORATIVA APLICADAS À ADMINISTRAÇÃO PÚBLICA}

\footnotetext{
${ }^{7}$ MORAES, Alexandre de. Reforma Administrativa: Emenda Constitucional no 19/98. 3. ed., São Paulo : Atlas, 1999, p. 30.
} 
As regras de governança são fundamentais para concretude e sustentabilidade das boas práticas de gestão administrativa no setor público.

Conforme assevera Paulo M. $\mathrm{Cruz}^{8}$, "não é mais suficiente somente o desenvolvimento de teorias jurídicas complexas e sofisticadas em relação a temas e institutos setoriais do complexo fenômeno da convivência humana".

É preciso concretizar regras, postulados e tornar prática todo o arcabouço teórico jurídico que orbita o Estado, em especial, a Administração Pública.

Para tanto, assim como no setor privado, o encadeamento de ações metodologicamente traçadas permite ao setor público alcançar os melhores resultados no menor espaço de tempo com menor ônus possível.

Além de Eficiência, falamos de eficácia e efetividade. No entanto, compreender o conceito operacional de Governança, este, emprestado do setor privado ao setor público, mostra-se saudável para edificação dos argumentos, ora apresentados.

Segundo Jensen ${ }^{9}$, governança são as regras vigentes de administração decorrentes do mais elevado escalão diretivo de uma organização, seja ela pública ou privada, as quais são invocadas sempre que algo em não conformidade mostrar-se no conjunto de ações ou no ato administrativo.

Trata-se de boas práticas e do desenvolvimento de ações que possibilitem resultados de qualidade e que atendam as finalidades do interesse público. No setor privado as organizações seguem diretrizes especificas de um sistema de governança corporativa com o objetivo de mitigar os riscos da organização.

Dessa forma, as instituições estabelecem mecanismos que lhes permitam o monitoramento e direção de forma estimulada, revestindo todos os atores nos resultados obtidos e os relacionando com a própria administração, pública ou privada. Fixando uma simbiose entre Estado (gestão pública) e o cidadão.

\footnotetext{
${ }^{8}$ CRUZ, Paulo Marcio. A sustentabilidade e o patrimônio cultural como elementos ambiental, social e econômico. p. 7-26. In Sustentabilidade e Meio Ambiente: relação multidimensional. Org. Maria Claudia da Silva Antunes de Souza. Rio de Janeiro: Lumen Juris, 2019.

9 JENSEN, Michael. A theory of the firm: governance, residual claims, and organizational forms. Harvard University Press, 2001. (tradução própria).
} 
Para o Instituto Brasileiro de Governança Corporativa (IBGC) 10 “governança corporativa é o sistema pelo qual as organizações são dirigidas, monitoras e incentivadas, envolvendo os relacionamentos entre os proprietários, conselhos de administração, diretoria e órgãos de controle".

Pela ausência de regras de governança corporativa no setor público é se constatar concretamente que há relativa desorganização administrativa, rigorismo excessivo nos órgãos e entidades da Administração Pública devido a uma burocracia gerencialista e a relativização das autonomias na tomada de decisão remanescentes da administração patrimonialista. ${ }^{11}$

Busca-se dar vida um discurso que afronta as razões pela qual o Estado foi concebido, administrar com qualidade e resultados positivos os interesses coletivos de seu povo, em cujos resultados somam-se a falta de capacitação de recursos humanos e os escassos investimentos orçamentários básicos para promover a boa administração.

Não obstante, as regras de governança no setor público demonstram uma disposição da Sociedade em promover uma transformação na forma de administrar do Estado, por meio de alterações substanciais na estrutura administrativa e de controle, organizacional, gerencial e de responsabilização por não conformidades detectadas.

A principal ideia nesse modelo gerencial é otimizar o desempenho da gestão administrativa da coisa pública com vistas a obter os melhores resultados pelo maior tempo possível, aperfeiçoando os processos e os canais de interlocução com o cidadão.

Sob a mesma designação de governança pública se pode adotar mecanismos estritamente adequados ao setor privado, em busca de conferir ao Estado melhoria do seu resultado econômico, numa perspectiva de análise do custo benefício e controle, mediante a importação de procedimentos de avaliação que levam em conta a preservação da despesa [...] sob o manto da governança pública, podese adotar diretrizes relacionadas aos objetivos de efetividade de justiça social e equidade, em prevalência a aferição do atingimento do fim público e melhoria da gestão nas políticas públicas em uma perspectiva de efetividade social ${ }^{12}$.

\footnotetext{
${ }^{10}$ INSTITUTO BRASILEIRO DE GOVERNANÇA CORPORATIVA (IBGC). Código das melhores práticas de governança corporativa. 4 ed. São Paulo: IBGC, 2009. p. 19.

${ }^{11}$ NOHARA, Irene Patrícia. Reforma administrativa e burocracia: impacto da eficiência na configuração do direito administrativo brasileiro. São Paulo: Atlas, 2012.

12 PESSOA, Leanne Araújo Holanda de Paula. Governança pública e efetividade no serviço público: uma análise do modelo gerencial na governança pública da administração federal. Direito administrativo e tutela jurídica dos direitos fundamentais. Organizadores: Cynara Monteiro Mariano; Felipe Braga Albuquerque; Lígia Maria Silva Melo De Casimiro. Curitiba: Editora Íthala, 2019. p. 266-283.
} 
Não obstante ser o critério da Eficiência um aspecto relevante nos ganhos governamentais das políticas de Estado apropriadas ao cidadão, o alcance da eficiência por meio da multiplicação de resultados, de uma forma ou de outra, reduzindo despesas ou melhor empregando (otimizando) os meios de forma mais efetiva e apropriada não podem, sob pena de prejuízo direto aos direitos fundamentais e sociais do cidadão, dos níveis permanentes de qualidade que se espera nas políticas sociais desenvolvidas pelo Estado.

Certo é que os instrumentos manejados pelo setor privado para bem gerir as empresas e grandes organizações foi adotado pelo setor público como uma solução viável para que os atos administrativos e de gestão fossem melhor realizados, com mais transparência buscando a eficiência como finalidade.

Além disso não se pode olvidar que a aplicação adequada das regras de governança corporativa pública produz, com efeito, resultados aferíveis e, portanto, capazes de alimentar relatórios governamentais acerca das consequências e aplicabilidade das políticas de governo.

No setor privado, Jensen ${ }^{13}$ “esclarece que governança é a estrutura de controle de alto nível, consistindo dos direitos de decisão do Conselho de Administração e do diretor executivo", o que poder-se-ia afirmar de outra banda, que a governança pública consiste no estabelecimento de regras de procedimento, coordenação e controle com vistas a balizar os atos administrativos e os atos de gestão com maior transparência e celeridade, sem desperdício do dinheiro público.

Outrossim, as regras de governança na Administração Pública permitem garantir ao cidadão receber Políticas Públicas de qualidade e excelência, em razão do aperfeiçoamento gerencial e técnico que se espera dos postulados ali estabelecidos.

Nesse sentido, havendo a possibilidade de mensurar e comparar resultados por meio de ferramentas qualificadoras confiáveis, poder-se-á estabilizar a análise dos dados promovendo verdadeiro fenômeno sustentável nos atos de gestão da Administração Pública.

\footnotetext{
13 JENSEN, Michael. A theory of the firm: governance, residual claims, and organizational forms.
} Harvard University Press, 2001. 
Todavia, o cerne da celeuma sobre o tema recai no conceito de sustentabilidade propriamente dita, posto que, conforme esclarece Veiga ${ }^{14}$, o substantivo "sustentabilidade" passou a servir sempre que invocado quando se quer expressar sinônimos de durabilidade e continuidade temporais.

O Fato é que o conceito de sustentabilidade foi banalizado e utilizado como sinônimo de Desenvolvimento sustentável, quando na realidade, são conceitos bastantes distintos, donde sustentabilidade, de fato, sob inúmeros critérios, expressa não apenas a continuidade ou perenidade de um fenômeno temporal, como também sua estabilidade e equilíbrio de valores sob o mesmo aspecto linear fenomênico.

Portanto, as regras de governança corporativa como pressupostos de eficiência e qualidade da gestão sustentável na Administração Pública é, sobretudo, a capacidade que dispõe a administração de realizar atos administrativos, na prestação de serviço ao cidadão, a partir de critérios objetivos dotados de transparência e controle, austeridade e economicidade, em caráter estável para todas as gerações.

Desde que a partir dos controles devidos aos atos de gestão, bem como, aos atos administrativos em geral, a Administração pública se utilize das ferramentas de governança pública, será possível a manutenção do aspecto sustentável sob os critérios: Social, Cultural, Ecológico, Ambiental, Territorial, Econômico e Político ${ }^{15}$.

Isso porque em todas as áreas mencionadas haverão políticas públicas sociais de Estado voltadas ao bem-estar comum e interesse público da Sociedade.

Considerando, assim, que Administração Pública, estrutura executiva do Estado, tem por dever implementar Políticas Públicas Sociais com eficiência e qualidade, bem assim, que as referidas Políticas devem ser realizadas sob a perspectiva da Transparência, Legalidade, Economicidade, Celeridade, entre outros aspectos, então, o manejo das regras de governança corporativa pública, mostrar-se-ão adequadas na produção de bons resultados e, sobretudo, estáveis, permanentes e equilibrados, ou seja, sustentáveis.

\footnotetext{
${ }^{14}$ VEIGA, José Eli Da. Para entender o desenvolvimento sustentável. São Paulo: editora 34, 2015, p.38. 15 SACHS, Ignacy. Caminhos para o desenvolvimento sustentável. Org. Paula Yone Stroh. Rio de Janeiro: Garamond, 2009, p. 85-87.
} 
Wald $^{16}$ define a governança como um conjunto de fatores essenciais para o funcionamento da administração de uma organização eficiente, destinados a promoção de um upgrade no desempenho dos setores que a ela se submetem, porquanto, aspectos relevantes de transparência nas contas e gastos, a equidade na forma de tratamento dos colaboradores, bem assim, a inserção de condutas éticas entre todos os atores do sistema público, são pressupostos essenciais de qualidade, eficiência e sustentabilidade a bem do interesse público.

\section{CONSIDERAÇÕES FINAIS}

As limitações impostas pela ausência de transparência e critérios objetivos, de medidas de controle e emprego eficiente e sustentável dos recursos orçamentários que abastecem o Estado são decorrentes da ausência de regras de governança corporativa no setor público. As inexistências dos respectivos regramentos impactam diretamente nas Políticas Públicas que atendem a Sociedade.

Tem-se que práticas de boa gestão fomentam novos investimentos e a elevação da qualidade de vida da Sociedade, promovendo medidas sustentáveis na gestão pública. Claramente se mostra como um pressuposto fundamental da administração da máquina estatal.

A aplicação de regras de governança como visto, provoca a maximização dos ganhos de eficiência e efetividade no produto entregue com a prestação de serviços ao cidadão.

Mecanismos que necessários ao gerenciamento planejado, ainda que emprestados do setor privado, e que possibilitem a estruturação metodológica da gestão administrativa do Estado, facilitam a vida do gestor público e evitam medidas judiciais que encerrem atos de improbidade administrativa, promovendo, sobretudo, o enfrentamento da corrupção no Estado Democrático.

\footnotetext{
${ }^{16}$ WALD, Arnoldo; MORAES, Luiza. Alguns aspectos do controle e da gestão de companhias no projeto de reforma da lei das sociedades por ações - considerações gerais. Revista de Direito Bancário, do Mercado de Capitais e da Arbitragem. São Paulo, v.3, n. 8, p. 13-30, abr./jun. 2000. p. 53.
} 
Controles, estatutos de ética, medidas de transparência e controle e prestação de contas promoveram resultados contabilizáveis de atuação responsável e elevação do desempenho da Administração pública.

Não obstante, fica evidente que o compartilhamento das regras de governança no setor público fez bem a gestão administrativa da estrutura funcional do Estado, porquanto, mostra-se como a superação da forma arcaica de administrar a coisa pública, tratando-se de um modelo inspirador de boas práticas na gestão pública, com lastro forte nos princípios constitucionais que orientam a Administração Pública, bem como, a Moralidade, Impessoalidade, Ética, Transparência e Efetividade dos Atos Administrativos.

Assim, infere-se que por meio da implementação e manejo de regras de governança no setor público é possível fomentar a existência de um maior envolvimento dos atores que viabilizam o nascimento, crescimento e expansão de Políticas Públicas voltados a Sociedade, porquanto, o envolvimento dos responsáveis na tomada de decisão seguir-se-á metodologicamente orientada.

Por fim, não se pode olvidar que as medidas de governança são pressupostos naturais para o evitamento dos desvios de recursos públicos e dos atos de corrupção que permeiam a coisa pública.

Desta forma, a legitimidade democrática do povo, cuja participação nas decisões da Administração Pública deve ser permanente, somente se tornam efetivas se os mecanismos colocados à disposição da população puderem oferecer qualificadoras eficientes e aferíveis no que tange a prestação de contas e resultados mensuráveis de qualidade das Políticas Públicas implantadas e disponíveis para a Sociedade.

Com efeito, considerar a existência e efetividade de regras de governança na Administração Pública nos permite conceber a evolução dos princípios objetivos do crescimento de uma Sociedade justa e concretizar a cidadania de uma Nação.

\section{REFERÊNCIAS}

ALFONSO, Luciano Parejo. Eficacia y administración: tres estudios. Madrid: Imprenta Nacional del Boletín Oficial del Estado, 1995. 
BRASIL. Constituição (1988). Constituição da República Federativa do Brasil. Brasília, DF: Senado Federal: Centro Gráfico, 1988.

CADORE, Diana Dalmolim; CADORE, Tiago. Desmistificando a sustentabilidade. Sustentabilidade e meio ambiente: relação multidimensional. Org. Maria Claudia da Silva Antunes de Souza. Rio de janeiro: Lumen Juris, 2019.

CRUZ, Paulo Marcio. A sustentabilidade e o patrimônio cultural como elementos ambiental, social e econômico. p. 7-26. In Sustentabilidade e Meio Ambiente: relação multidimensional. Org. Maria Claudia da Silva Antunes de Souza. Rio de Janeiro: Lumen Juris, 2019.

CAMARGO, Ricardo Antônio Lucas. Breve introdução ao direito econômico. Porto Alegre: Sérgio Antônio Fabris. 1993, p.22.

CANOTILHO, J.J. Gomes; MOREIRA, Vital. Constituição da República Portuguesa Anotada. 3. ed. Coimbra: Coimbra, 1993.

COSTODIO FILHO, Ubirajara. A Emenda Constitucional 19/98 e o Princípio da Eficiência na Administração Pública. In: Cadernos de Direito Constitucional e Ciência Política. São Paulo: Revista dos Tribunais. n. 27, p. 210-217, abr./jul. 1999.

DI PIETRO, Maria Sylvia Zanella. Direito Administrativo. 12 ed., São Paulo: Atlas, 2000.

DWORKIN, Ronald. Talking Rights Seriously. Cambridge: Harvard University, 1978.

FRANÇA, Vladimir da Rocha. Eficiência administrativa. In: Revista de Direito Administrativo. Rio de Janeiro: Renovar, n. 220, abr./jul. 2000, p. 168.

GRAU, Roberto Eros. A ordem econômica na Constituição de 1988. 2. ed., São Paulo: Malheiros., 1991.

GUIMARÃES, Fernando Augusto Mello. Rui: Uma Visão do Controle do Dinheiro Público - uma análise contemporânea. In: BRASIL, Tribunal de Constas da União. Rui Barbosa: uma visão do controle do dinheiro público - Brasília: Tribunal de Contas da União, Instituto Serzedllo Corrêa, 2000.

HOUAISS, Antônio. VILLLAR, Mauro de Salles. Minidicionário Houaiss da Língua Portuguesa. Rio de Janeiro: Objetiva, 2004.

JUCÁ, Francisco Pedro; MONTESCHIO, Horácio; MONTESCHIO, Valéria Juliana Tortato. Administração pública eficiente e a necessidade da garantia de assegurar os direitos fundamentais efetivamente aos brasileiros. Percurso, [S.1.], v. 3, n. 26, p. 242 - 267, dez. 2018. ISSN 2316-7521. Disponível em: 〈http://revista.unicuritiba.edu.br/index.php/percurso/article/view/3143/371371675>.

Acesso em: 25 abr. 2020. 
LOPES, Maurício Antônio Ribeiro. Comentários à Reforma Administrativa: de acordo com as Emendas Constitucionais 18, de 05.02.1998, e 19, de 04.06.1998. São Paulo: Revista dos Tribunais, 1998. p. 108.

MORIN, Edgar. O método 3. O conhecimento do conhecimento. Trad. Juremir Machado da Silva. 5. ed. Porto Alegre: Editora Sulina, 2015.

MELlO, Celso Antônio Bandeira de. Curso de Direito Administrativo. ed. 12, São Paulo: Malheiros, 1999.

MORAES, Alexandre de. Reforma Administrativa: Emenda Constitucional no 19/98. 3. ed., São Paulo: Atlas, 1999.

MOREIRA NETO, Diogo de Figueiredo. A Lei de Responsabilidade Fiscal e seus Princípios Jurídicos. In: Revista de Direito Administrativo. Rio de Janeiro: Renovar, $\mathrm{n}^{\circ}$ 221, jul./set. de 2000.

MOREIRA NETO, Diogo Figueiredo. Mutações do Direito Administrativo. Rio de Janeiro: Renovar, 2000.

NOHARA, Irene Patrícia. Reforma administrativa e burocracia: impacto da eficiência na configuração do direito administrativo brasileiro. São Paulo: Atlas, 2012.

NUNES CARVALHO SOBRAL DE SOUZA, Patrícia Verônica; da silva neto, romeu. Perspectivas das cidades inteligentes na administração pública em tempos de transformação digital. Relações Internacionais no Mundo Atual, [S.l.], v. 1, n. 26, p. 65 90, abr. 2020. ISSN 2316-2880. Disponível em: <http://revista.unicuritiba.edu.br/index.php/RIMA/article/view/3973/371372302 >. Acesso em: 25 abr. 2020. doi:http://dx.doi.org/10.21902/Revrima.v1i26.3973.

RODRIGUES, Maria Lúcia de Barros; OLIVEIRA, Pamela Danelon Justen de; ARAUJO, Alexandra Barbosa Campos de. Compliance no setor estatal. Percurso, [S.1.], v. 2, n. 19, p. 279, fev. 2017. ISSN 2316-7521. Disponível em: $\langle$ http://revista.unicuritiba.edu.br/index.php/percurso/article/view/259/1437>. Acesso em: 25 abr. 2020.

PESSOA, Leanne Araújo Holanda de Paula. Governança pública e efetividade no serviço público: uma análise do modelo gerencial na governança pública da administração federal. Direito administrativo e tutela jurídica dos direitos fundamentais. Organizadores: Cynara Monteiro Mariano; Felipe Braga Albuquerque; Lígia Maria Silva Melo De Casimiro. Curitiba: Editora Íthala, 2019.

SACHS, Ignacy. Caminhos para o desenvolvimento sustentável. Org. Paula Yone Stroh. Rio de Janeiro: Garamond, 2009.

SILVA, Júlio César da. Reforma Administrativa Brasileira e a Terceirização no Setor Público. In: Revista de Direito Administrativo. Rio de Janeiro: Renovar, n. 217, p. 1330, jul./set. 1999. 
TALOR Frederick Winslow. Princípios de Administração Científica. Trad. Arlindo Vieira Ramos. 8. ed. São Paulo: Atlas, 1990.

TOURAINE, Alain. Crítica da modernidade. Rio de Janeiro: Vozes, 1994.

VEIGA, José Eli Da. Para entender o desenvolvimento sustentável. São Paulo: editora 34, 2015.

VIEIRA, Rejane Esther. Políticas públicas e os novos direitos: o novo enfoque da gestão pública na construção de espaços públicos de participação no estado de direito no Brasil. Revista Jurídica, [S.1.], v. 21, n. 5, p. 11-43, jun. 2008. ISSN 2316$753 X$. abr. 2020. doi:http://dx.doi.org/10.21902/revistajur.2316-753X.v21i5.114. 